\title{
Integrative transcriptome and microRNome analysis identifies dysregulated pathways in human Sertoli cells exposed to TCDD
}

\author{
Mariana A. Ribeiro ${ }^{\mathrm{a}}$, Molly S. Estill ${ }^{\mathrm{b}}$, Geysson J. Fernandez ${ }^{\mathrm{a}}$, Leonardo N. Moraes ${ }^{\mathrm{a}}$, \\ Stephen A. Krawetz ${ }^{\text {b, }}$, Wellerson R. Scarano ${ }^{\text {a,* }}$ \\ a Department of Morphology, Institute of Biosciences, UNESP- Univ. Estadual Paulista, Botucatu, SP, 18618-689, Brazil \\ ${ }^{\mathrm{b}}$ Department of Obstetrics and Gynecology, Wayne State University School of Medicine, Detroit, MI, 48201, United States \\ ${ }^{c}$ Center for Molecular Medicine and Genetics, C. S. Mott Center for Human Growth and Development, Wayne State University School of Medicine, Detroit, MI, 48201, \\ United States
}

\section{A R T I C L E I N F O}

\section{Keywords:}

Sertoli cell

TCDD

miRNA

RNAseq

Infertility

\begin{abstract}
A B S T R A C T
Male fertility and spermatogenesis are directly linked to the Sertoli cell's ability to produce factors associated with germ cell development. Sertoli cells express receptors for FSH and testosterone, and are the major regulators of spermatogenesis. Recent studies report that regulatory RNA molecules, such as microRNAs (miRNAs), are able to modulate testicular function during spermatogenesis and that their altered expression may be involved in male infertility. miRNAs may play a role in the response to xenobiotics that have an adverse consequences to health. An important group of xenobiotic organic compounds with toxic potential are dioxins, such as 2,3,7,8-tetrachlorodibenzo-p-dioxin (TCDD). Experimental models of TCDD exposure in mice demonstrated that TCDD exposure causes low sperm count and delayed puberty. This study below examines the mechanism of TCDD's action in human Sertoli cells, through interrogating the expression profile of miRNAs and mRNAs, that enabled us to identify dysregulated molecular pathawys in Sertoli cell. 78 miRNAs presented altered expression, with positive regulation of 73 and negative regulation of 5 miRNAs when compared to the control group. Regarding gene expression profile, 51 genes were deregulated, of which 46 had positive regulation and 5 genes with negative regulation. Important pathways have been altered by the action of TCDD as AhR pathway, GPR68, FGF2 and LIF. This study has opened the door to new perspectives on the TCDD toxicity pathway as it affects Sertoli cells physiology that can ultimately lead to male infertility.
\end{abstract}

\section{Introduction}

The disruption of male reproductive health is increasing in frequency in industrialized countries. Environmental pollution has been suggested as the main source (Sharpe et al., 2003).

Endocrine disruptors are estrogen-like and/or anti- androgenic chemicals in the environment that have potentially hazardous effects on male reproductive axis capable of triggering morphological and functional changes (Sikka and Wang, 2008). Studies in animals showed that the environmental contaminant 2,3,7,8-tetrachlorodibenzo-p-dioxin (TCDD) is toxic and detrimental to human health (Denison and Nagy, 2003), its effect was clearly evident after the Seveso accident (Bertazzi et al., 2001; Warner et al., 2013). TCDD is introduced to our environment largely as an unwanted by-product of manufacturing, such as incineration and burning of fossil fuels, although volcanic eruptions and forest fires also contribute to the overall environmental burden of dioxins. Among human and animal populations, ingestion of contaminated food is the primary source of dioxin exposure (Schecter et al., 2002; Harrad et al., 2003; Pompa et al., 2003; Malisch and Kotz, 2014). Wolf et al. (1999) reported that the administration of low doses of TCDD during gestation, in mice, alters the reproductive development of the fetus. In females this leads to a reduction of the uterine weight and in male can decrease fertility.

The male gonad, i.e., testis, consists of seminiferous tubules surrounded by a fibrous coat, tunica albuginea. Inside the seminiferous tubules are large Sertoli cells, supported by the basement membrane of the germinal epithelium, which act as the nurse cells for germ cell development (Croxford et al., 2011). Sertoli cells are pyramidal somatic cells with a large surface area, supporting the development of a large number of germ cells in the estimated ratio of 1:50 in the adult rat testis

\footnotetext{
* Corresponding author.

E-mail addresses: ribeiro.mantunes@gmail.com (M.A. Ribeiro), mestill@med.wayne.edu (M.S. Estill), jasonfergar@hotmail.com (G.J. Fernandez), leonardonmunesp@gmail.com (L.N. Moraes), aa1965@wayne.edu (S.A. Krawetz), scarano@ibb.unesp.br (W.R. Scarano).
} 
(Weber et al., 1983). Sertoli cell number can determine testicular size, the number of spermatogonial stem cells in the testis and spermatid production. They are responsible for providing an immunologically privileged and highly specialized environment inside the seminiferous tubules. Sertoli cells are connected by gap junctions, enabling chemical and ion exchange, helping to coordinate the seminiferous epithelium cycle (Mruk and Cheng, 2004; Gao et al., 2015). Adjacent Sertoli cells are joined by tight junctions in the lateral membrane, which creates the Blood-Testis Barrier (BTB) (de Freitas et al., 2016). At the onset of meiosis, germ cells beyond the BTB move into the adluminal compartment of the seminiferous tubule, and become dependent on Sertoli cells to provide nutrients and growth factors for their development (Cheng and Mruk, 2004). Therefore, any compound that disturbs Sertoli cell function could disrupt spermatogenesis, ultimately leading to male infertility.

The canonical TCDD pathway is though aril hydrocarbon receptor (AhR) that is an important regulator of the male reproductive tract (Hansen et al., 2014). When AhR is inactive, it binds to a chaperone in the cytoplasm. Upon interaction with the ligand, i.e., TCDD, AhR is activated and dissociates from the chaperone, translocating to the nucleus to interact with ARNT (aryl hydrocarbon receptor nuclear translocator). The AhR/ARNT complex becomes active and binds to Xenobiotics Responsive Elements (XRE) throughout the genome, thereby modifying the expression of various genes, mainly AHRR, CYP1A1 and CYP1B1, triggering a cellular response (Jackson and Mitchell, 2011). Among the genes that are triggered by AhR/TCDD is AHRR that competes with ARNT to bind to AhR, thus repressing the cellular TCDD pathway. TIPARP is also an AhR target gene that is expressed in many different tissues, including liver, heart, spleen, brain, and reproductive organs. MacPherson et al. (MacPherson et al., 2014, 2013a) recently showed that TIPARP is a transcriptional repressor of AhR. This, revealed a novel negative feedback loop in AhR signaling.

TCDD could affect the expression of a variety of genes dependent on the organism and cell type including those that participate in the inflamatory response pathways like Il1B and LIF. Similarly, small nocoding RNAs (sncRNAs) might play an important role when responding to xenobiotics and impact health. Recent studies suggest that small noncoding regulatory RNAs (sncRNA), such as microRNAs, can modulate testicular function during spermatogenesis and that their altered expression may be factors involved in male infertility (Abu-Halima et al., 2013; Lian et al., 2009).

There is a lack of data regarding the role of miRNAs and mRNAs in human Sertoli cells as regulatory factors of human spermatogenesis. There are no previous studies about potential effects of TCDD on the response of microRNAs from male reproductive cells. Thus, the identification of miRNAs as targets for TCDD, inducing altered gene expression, offers a new path to understand the toxicological mechanisms and the role of environmental pollutants on male reproductive tract.

\section{Material and methods}

\subsection{Culture, chemicals and cellular stress}

Human primary Sertoli cells (HSeC) were purchased from Lonza (USA). Cells were cultured in Dulbecco's modified Eagle's medium (DMEM/Ham F12) (Sigma Aldrich, St. Louis, MO, USA)([1/1] v/v, supplemented with $15 \%$ fetal bovine serum, $100 \mathrm{U} / \mathrm{ml}$ penicillin, 100 $\mu / \mathrm{ml}$ streptomycin and $0.25 \mu \mathrm{g} / \mathrm{ml}$ fungizone (Gibco, Invitrogen, USA). Cells were incubated with TCDD (Sigma Aldrich, St. Louis, MO, USA), diluted in culture medium and DMSO as a carrier to $0.05 \%$, achieving a $10 \mathrm{nM}$ concentration of the chemical; concentration was determined after MTT assay (Mosmann, 1983). Exposure was performed in triplicate for $72 \mathrm{hs}$, including a control group also in triplicate, exposed to $0.05 \%$ DMSO for the same time period. Sertoli cells were divided into aliquots containing approximately $1 \times 10^{6}$ cells and subsequently underwent total RNA and protein extraction.

\subsection{Total RNA extraction}

RNA extraction was performed with Trizol (Ambion, USA) with 1\% of $\beta$-Mercaptoethanol, following manufacturer's instructions. The RNA was quantified by spectrophotometry using a NanoDrop (Thermo Scientific, USA). RNA quality, as measured with ribosomal RNAs by the RNA Integrity Number (RIN), was obtained using the 2100 Bioanalyzer system (Agilent, USA).

\subsection{1. mRNA purification, library construction, and sequencing}

RNAs were sequenced using the HiSeq2500 platform (Illumina) within the provision of Animal Biotechnology Laboratory Services, School of Agriculture Luiz de Queiroz (ESALQ). A single $500 \mathrm{ng}$ aliquot of total unfractionated RNA was submitted for library construction, and sequencing. During library preparation Ribo-Zero rRNA Removal Kit (Illumina,USA) was used for rRNA depletion. Messenger RNA purification and library construction was carried out with total RNA using the mRNA TruSeq Stranded LT Sample Preparation Kit (Illumina), following the manufacturer's specifications. The sequencing was performed with the HiSeq Sequencing System using the sequencing by synthesis methodology with modified chemical and labeled with fluorescent nucleotides.

\subsubsection{High performance sequencing - sncRNAs}

A single $500 \mathrm{ng}$ aliquot of total unfractionated RNA was also submitted to the Animal Biotechnology Laboratory sequencing facility for library construction, and sequencing of sncRNAS. The construction of the sncRNAs libraries was performed using the TruSeq Small RNA Sample Preparation Kit following the manufacture's protocol. The sequencing was also performed with the HiSeq Sequencing System using the sequencing by synthesis methodology with modified chemical and labeled with fluorescent nucleotides.

\subsubsection{Sequencing analysis}

To determine the levels of each RNA, RNA-seq reads were mapped to the Human reference genome hg38 ("http://www.gencodegenes. org/," n.d.) using HiSat (Kim et al., 2015). Raw data were calculated as the TPM (Transcripts per Million mapped) of each gene in each sample using RSEM (Li and Dewey, 2011). Genes with a TPM of zero in one or more samples were excluded from analysis. Filtered data were logarithmically transformed and normalized using a normalization method by DESeq2 and EBSeq $(26,27)$. A Log 2 Fold Change (Log2 FC) between TCDD and control groups was calculated of each gene pair. Differentially expressed genes were determined by adjusting Log2 FC $<-0.41$ or $>0.26$ [False Discovery rate (FDR)- corrected p-value $\leq 0.05$ ] when comparing the experimental groups.

For miRNA analysis, all the reads were demultiplexed according to their index sequences using CASAVA version 1.8 (Illumina) and reads that did not pass the Illumina chastity filter were removed from the dataset. Small RNA sequencing reads of good quality were subjected to analysis by sRNAbench toolbox (Rueda et al., 2015). Data analysis included read quality assessment using FastQC (Andrews, 2010) and read cleaning assessment by CutAdapt (Chen et al., 2014). Read alignment was performed using Bowtie1 (Langmead et al., 2009) followed by HTSeq (Anders et al., 2014) for annotation and quantification of aligned sequences. Lastly sncRNA tags were annotated also using the RepeatMasker library (Kent et al., 2002). Raw data were calculated as normalized mean count in each sample. Data normalization (Robinson and Oshlack, 2010) and differential expression analysis was performed using edgeR (Bioconductor/R) v.3.0 (Gentleman et al., 2004; Robinson et al., 2010), which implements a negative binomial distribution, to identify differential miRNAs (Anders and Huber, 2010). Read counts were transformed logarithmically and normalized using a quantile normalization method. For each miRNA, fold change between case and control was calculated. Differentially expressed miRNAs were determined by adjusting $\log 2 \mathrm{FC}<-0.60$ or $>0.58$ with FDR- corrected 
p-value $\leq 0.05$

\subsubsection{Prediction of target miRNAs}

miRNA targets that could change the expression of their corresponding mRNAs were assessed computationally. To test this hypothesis, miRNA prediction algorithms were applied to the differentially expressed mRNAs. Prediction of potential miRNA targets was accomplished using Mirwalk 2.0 (Dweep et al., 2011a). This tool integrates miRNA data available from 12 different prediction algorithms and databases: miRWalk (Dweep et al., 2011a), miRNAmap (Hsu et al., 2008) mirDB (Wong and Wang, 2015), Diana MicroTv4 (Maragkakis et al., 2009), miRmap (Vejnar et al., 2013), RNAhybrid 2.1 (Rehmsmeier et al., 2004), miBridge (Tsang et al., 2010), miRanda (Betel et al., 2008), PicTar2 (Anders et al., 2012), PITA (Kertesz et al., 2007), RNA22v2 (Loher and Rigoutsos, 2012) and TargetScan (Friedman et al., 2009). The input for Mirwalk was the miRNAs with differentially expression between TCCD exposure and control. mRNA transcripts predicted to be miRNA targets in at least six databases were considered in subsequent analyses.

\subsubsection{Data interpretation}

The data presented below describe the human Sertoli cells' transcriptome and microRNome after exposure to $10 \mathrm{nM}$ TCDD for $72 \mathrm{~h}$. To interpret this data in context of known genomic, RNA and protein interactions, we used a series of programs, discussed below:

1- Ingenuity Pathway Analysis program (IPA; Redwood City, CA, USA): functions Core Analysis, Mechanistic Networks, Pathway Analysis, Canonical Pathways, MicroRNA Target Filter and Path Designer.

2- Genomatix Software Suite (Genomatix Software GmbH, Munich, Germany: functions: Genomatix Pathway System (GEPS), Genomatix Annotation (Eldorado), Matbase (Transcription Factor Database).

\subsubsection{Validation of miRNA and $m R N A$ expression}

Significantly dysregulated miRNAs and mRNAs were validated by qPCR confirming RNA seq results. cDNA was synthesized using TaqMan H microRNA Reverse Transcription kit (Life Technologies, USA), combined with Stem-loop RT Primers (Life Technologies, USA) and High Capacity RNA-to-cDNA Master Mix (Life Technologies, USA) according the manufacturer's guidelines. For miRNA, $3 \mu \mathrm{l}(10 \mathrm{ng})$ total RNA was mixed with specific primers $(3 \mu \mathrm{l})$, dNTPs $(100 \mathrm{mM})$, MultiScribeTM Reverse Transcriptase $(50 \mu \mathrm{l}), 10 \mathrm{X}$ RT Buffer, RNase inhibitor $(20 \mu \mathrm{l})$ and completed up to $4.5 \mu \mathrm{l}$ with $\mathrm{H}_{2} \mathrm{O}$. The corresponding miRNA templates were prepared: $16{ }^{\circ} \mathrm{C}$ for $2 \mathrm{~min}, 42{ }^{\circ} \mathrm{C}$ for $1 \mathrm{~min}, 50{ }^{\circ} \mathrm{C}$ for $1 \mathrm{~s}$ and $85{ }^{\circ} \mathrm{C}$ for $5 \mathrm{~min}$. Similarly the cDNA templates were prepared using $10 \mu \mathrm{l}$ total RNA was mixed with $4 \mu \mathrm{l}$ Master Mix, $2 \mu \mathrm{l}$ specific primers and completed up to $20 \mu \mathrm{l}$ with $\mathrm{H}_{2} \mathrm{O}$. The synthesis conditions were: 25 ${ }^{\circ} \mathrm{C}$ for $5 \mathrm{~min}, 42{ }^{\circ} \mathrm{C}$ for $30 \mathrm{~min}$ and $85{ }^{\circ} \mathrm{C}$ for $5 \mathrm{~min}$.

\subsubsection{Real-time quantitative PCR (miRNAs)}

Each cDNA of miR-106b-5p, miR-3613-3p and miR-18a-3p was quantified by real-time quantitative PCR using the Step One Plus Detection System (Life Technologies, USA). We used, for each reaction, $10 \mu \mathrm{l}$ TaqMan $\mathrm{H}$ Universal PCR Master Mix, $2 \mu 1$ TaqMan MicroRNA Assay Mix (Life Technologies, USA), $1.5 \mu \mathrm{l}$ cDNA and completed up to $20 \mu$ reaction volume. The cycling conditions were: $95{ }^{\circ} \mathrm{C}$ for $10 \mathrm{~min}$; 45 cycles of $95{ }^{\circ} \mathrm{C}$ for $15 \mathrm{~s}$ and $60{ }^{\circ} \mathrm{C}$ for $1 \mathrm{~min}$.

\subsubsection{Real-time quantitative PCR ( $m R N A s$ )}

For the analysis of expression level of AHRR, CYP1B1, FGF2, GPR68 and LIF, RT-qPCR was carried out with SYBR green Master Mix, using specific primers for each gene (Supplementary Table 1). Reactions were set up in a total volume of $20 \mu \mathrm{L}$ using $5 \mu \mathrm{l}$ of cDNA (diluted 1:100), $10 \mu \mathrm{l}$ SYBR green Master Mix (Life Technologies, USA) and $2.5 \mu \mathrm{L}$ of each specific primer $(5 \mathrm{nM})$ and performed in the Step One Plus realtime PCR system (Life Technologies, USA). The cycling conditions were:
$95{ }^{\circ} \mathrm{C}$ for $10 \mathrm{~min} ; 45$ cycles of $95{ }^{\circ} \mathrm{C}$ for $15 \mathrm{~s}$ and $60{ }^{\circ} \mathrm{C}$ for $1 \mathrm{~min}$.

\subsubsection{Analysis of the gene expression}

To analyze the differential expressions, the miRNA or mRNA levels obtained for each gene (Supplementary Table 1) were compared with TCDD with respect control group. Normalization of miRNA expression was used the expression of the snRNA U48 and RPL 21 reference genes and for mRNA expression, the gene B2M. Relative gene expression was evaluated using the comparative quantification method (Livak and Schmittgen, 2001). All relative quantifications were assessed using DataAssist $\mathrm{v} 3.0$ by $\Delta \Delta \mathrm{CT}$ method.

\subsection{Western blot analysis}

Protein expression was determined using western blot. Protein extraction was performed with RIPA lysis buffer as described previously (de Freitas et al., 2016). Aliquots $(80 \mu \mathrm{g}$ of protein) were treated with Laemli sample buffer (Bio-Rad, Hercules, CA, USA) and $\beta$-mercaptoethanol at $95{ }^{\circ} \mathrm{C}$ for $1 \mathrm{~min}$. Proteins were separated by $10 \%$ SDS-PAGE then transferred to a nitrocellulose membrane. Nonspecific protein binding was blocked by incubating the membrane in 5\% skim milk in Tris-HCl buffer containing $0.2 \%$ Tween 20 (TBST) for $30 \mathrm{~min}$ at room temperature. Membranes were subsequently incubated with the following primary antibodies: anti-AHRR (Santa Cruz Biotechnology, Dallas, TX, USA; cat\# SC-293297, primary antibody dilution: 1:100) and anti- $\beta$-actin (Santa Cruz Biotechnology Dallas, TX, USA; cat\# SC47778, primary antibody dilution: 1:600) in 3\% skim milk diluted in TBST overnight at $4 \circ \mathrm{C}$. After washing, membranes were incubated with specific HRP secondary antibody (IgG goat-anti rabbit, cat\# ab97051, Abcam Inc., Cambridge, UK; 1:35000 or IgG goat-anti mouse, cat\# ab97023, Abcam Inc., Cambridge, UK; 1:10000) in 3\% bovine serum albumin (BSA) diluted in Tris Buffered Saline with Tween ${ }^{\circledR} 20$ (TBST) for $2 \mathrm{~h}$. Immuno reactive components were revealed by chemiluminescence (AmershamTM ELC Select TM Western Blotting Detection Reagent, GE Healthcare ${ }^{\circledast}$, UK). Immunoreactive bands were calculated using image analysis software (ImageJ Software). $\beta$-actin was used as endogenous positive control, and results were expressed as mean \pm S.D. Immunoblotting concentrations (\%) were represented as optical densitometry values (band intensity - pixels).

\section{Results}

\subsection{Differentially expressed genes and miRNAs identified by RNA- sequencing}

Differential expression of mRNAs between the experimental groups was examined using DESeq2 and EBSeq (Leng et al., 2015). Differential expression was determined with a false discovery rate (FDR) less than 0.05 after Benjamini-Hochberg multiple-testing correction (Benjamini and Hochberg, 1995), as well as log2 fold change less than -0.41 or greater than 0.26 . Overall, sample analysis showed that 51 genes were dysregulated as summarized in Supplementary Table 2. Of those, 46 were up regulated including CYP1B1, IL1B, LIF, TIPARP and GPR68 and 5 genes were down regulated including VCAM1, compared to the control group.

Differential expression of miRNAs between the experimental groups was determined using edgeR (Robinson et al., 2010). Differentially expressed miRNAs were detected at a $0.58<\log 2 \mathrm{FC}>-0.60$ with a false discovery rate (FDR) $<0.05$ after multiple-testing correction (Benjamini -Hochberg) (Benjamini and Hochberg, 1995). As summarized in Supplementary Table 3, 78 miRNAs showed altered expression, with upregulation of 73 miRNAs including miR-106b-5p and down regulation of 5 miRNAs including miR-3613-3p and miR-18a-3p when comparing TCDD samples to the control group. 
miRNAs expression



TCDD $72 \mathrm{~h}$

Fig. 1. Relative miRNAs levels (log2 fold change) of Sertoli cells exposed to $10 \mathrm{nM}$ TCDD for $72 \mathrm{~h}$ compared to no exposed cells (control).

\section{2. miRNAs target prediction}

MirWalk 2.0 suggested that 10 different miRNAs exhibited altered expression that could effect 22 genes as summarized in Supplementary Table 4. For example, expression of mir-18a-3p is down regulated, while its two target genes GPR68 and CYP1B1 are up regulated. GPR68 plays a key role in the intracellular $\mathrm{pH}$ balance and CYP1B1 is an oxidative stress marker, belonging to the TCDD pathway impacting Sertoli cells.

Known Sertoli cell associated miRNAs and mRNAs identified by RNA-Seq were validated by TaqMan PCR. This included mir-106b-5p, mir-3613-3p and mir-18a-3p. Among the dysregulated mRNAs, CYP1B1, FGF2, IL1B, LIF, TIPARP, VCAM1 and GPR68 were validated by Sybr PCR. In addition, AHRR was also cross- validated as it is associated with the repression of the TCDD pathway. Consistent RNA-Seq and qPCR expression trends were observed in Fig. 1 and 2; Supplementary Tables 5 and 6 .

\subsection{TiPARP a negative regulator of AHR in Sertoli cells}

TiPARP was first reported to be a TCDD-responsive gene that was regulated by AHRR in mouse hepatoma cells (12). Subsequently, MacPherson et al. (2013a, 2013b) showed that TIPARP was a novel transcriptional repressor of AHRR. As shown in Fig. 3, the level of Sertoli cell TIPARP mRNA increased after a $72 \mathrm{~h}$ exposure to TCDD. This suggested that the canonical repressor gene and protein might be activated. As shown in Fig. 3, AHRR did not show any difference in RNA

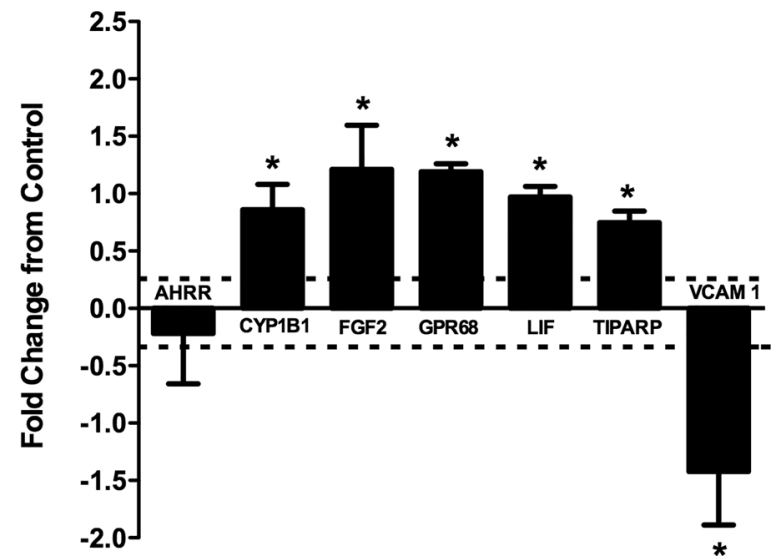

Fig. 2. Relative mRNAs levels (log2 fold change) of Sertoli cells exposed to $10 \mathrm{nM}$ TCDD for $72 \mathrm{~h}$ compared to no exposed cells (control).

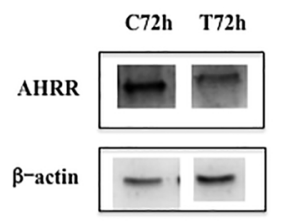

A

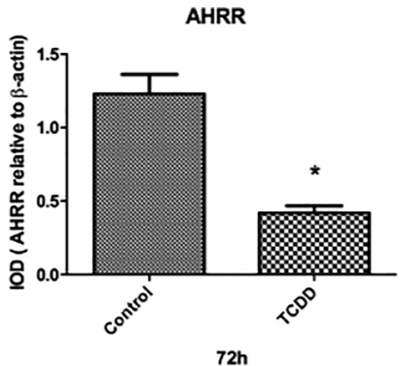

B
Fig. 3. A. Representative bands for AHRR and $\beta$-actin proteins from experimental groups treated with $10 \mathrm{nM}$ TCDD for $72 \mathrm{~h}$. Each band represents a pool with samples of three cell cultures obtained by Western Blot assay. B. The graph represents the relative expression of integrated optical density for AHRR on Sertoli cells treated with $10 \mathrm{nM}$ TCDD. Optical density was normalized by $\beta$ actin and was expressed as mean \pm SEM. The asterisk represents a statistically significant difference $(p \leq 0.05)$.

level as determined by RNA-seq or qPCR. However, its corresponding protein was significantly down regulated after $72 \mathrm{~h}$, consistent with a post transcriptional regulatory mechanism.

\section{Discussion}

Studies conducted in the last ten years have shown that the Sertoli cell is one of the main targets of environmental toxicants (Boekelheide, 2005; Gao et al., 2015). Most data shows the effects of TCDD in different cell types after a short exposure time (e.g., $24 \mathrm{~h}$ ). Aly and Khafagy (2011) demonstrated that TCDD induced oxidative stress in rat Sertoli cells after, 24, 48 and $72 \mathrm{~h}$ of exposure. Lai et al. (2005) also studied rat Sertoli cells exposed to TCDD for $24 \mathrm{~h}$ and they concluded that TCDD exposure might interfere with normal Sertoli cell functions as the expression of specific genes: sertolin and testin, the gene makers for cell-cell interactions were altered. MacPherson et al. (2013b) evaluated the mechanism repression of TCDD pathway on human breast carcinoma cells exposed to TCDD for maximum of $24 \mathrm{~h}$ and they found that TIPARP could also repress TCDD pathway in other way comparing to ARHH, the canonical repressor (MacPherson et al., 2013b). Wu et al. (2004) analyzed genomic DNA methylation status of imprinted genes in rat embryos exposed to TCDD and concluded that TCDD influences the expression level of imprinted genes, and affects fetal development.

Primary cultures of Sertoli cells (Lui et al., 2003; Qiu et al., 2013; Xiao et al., 2014) provide a reliable model to study Sertoli cell blood-testis barrier (BTB) function and to monitor effects of xenobiotics on testicular function. Our primary goal was to evaluate the effects of long-term exposure. We used a $72 \mathrm{~h}$ cell culture exposure as a model of chronic in vitro exposure. To the best of our knowledge, this is the first comparative study to define the miRNAs and mRNAs response of human Sertoli cells after exposure to TCDD.

After a $72 \mathrm{~h}$ exposure of human Sertoli cells to TCDD, 51 genes encoding mRNAs were differentially expressed compared to the control group. Forgacs et al. (2013) showed that after $48 \mathrm{~h}$ of TCDD exposure, using the same dose, in human hepatocytes in vitro, 540 genes were differentially expressed compared to the control group. The difference in the level of response is not surprising considering that liver is the primary detoxification organ. This is supported by a recent study (Houlahan et al., 2015) showing that after a $23 \mathrm{~h}$ TCDD exposure only minimal transcriptional dysregulation in rat hypothalamus (6 genes significantly altered in Long-Evans rats and 15 genes in Han/Wistar rats) were observed.

In comparison, the effect of TCDD-exposure on the microRNome revealed a total of 78 differentially expressed miRNAs when compared to the control group. Among these, 73 were up regulated, including mir106b-5p, which has been predicted as a possible modulator of AhR 


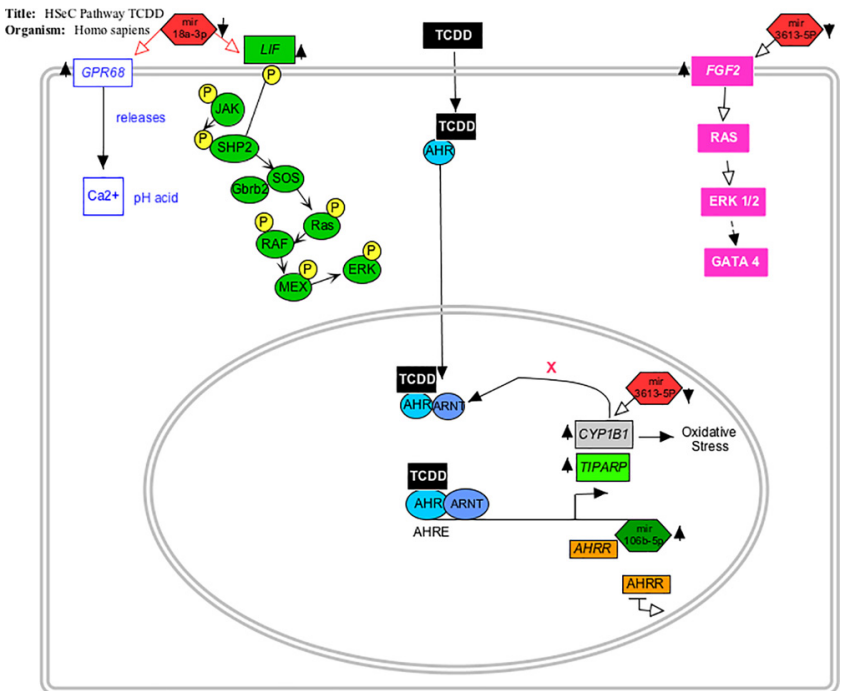

Fig. 4. Altered pathways in human Sertoli cells exposed to TCDD. GPR68 is up regulated and is used to maintain $\mathrm{pH}$ balance. In dark green is the regulation of LIF-mediated signaling pathway. In pink is FGF2 pathway that regulates GATA4 expression, a main protein for Sertoli cell physiology. TIPARP is highlighted in light green as a repressor of the pathway. The pathway was drawn using PathVisio-MIM (Luna et al., 2011) (For interpretation of the references to colour in this figure legend, the reader is referred to the web version of this article).

Repressor (AHRR) expression in various informatics analyses (mirDb (Wang and Wong, 2015), TargetScan (Friedman et al., 2009), Miranda (Betel et al., 2008), MirWalk (Dweep et al., 2011b). As we have shown by both RNAseq and confirmed by qPCR, AHRR expression does not change after $72 \mathrm{~h}$ TCDD exposure. In comparison, the level of the AHRR protein is significantly diminished after exposure to TCDD. This is consistent with a translational based miR mediated mechanism as summarized in Fig. 4. miR-106b-5p may repress productive translation of AHRR through partial complementarity to the mRNA, therefore mRNA is not cleaved but the respective miRNA does have a suitable constellation of complementary sites that causes post translational repression (Bartel et al., 2004). This is a very important pathway that requires consideration since AHRR regulates the TCDD pathway. Overall, in the case of aberrant AHRR expression, cellular response to TCDD could be compromised.

Interestingly, TCDD-inducible poly (ADP-ribose) polymerase (TIPARP) was overexpressed. It is a member of the poly (ADP)-ribose polymerase (PARP) family that uses NAD as a substrate to transfer ADPribose onto target proteins (MacPherson et al., 2013a) inducing a posttranslational modification. It is involved in several biological processes, such as immune cell function, the regulation of transcription, and DNA repair. MacPherson et al. (2013a,b, 2014) have recently shown that TIPARP is a transcriptional repressor of AhR, as part of a negative feedback loop in AhR signaling. This parallels the decreased protein expression of AHRR, the canonical repressor of AhR pathway that we observed in human Sertoli cells after a $72 \mathrm{~h}$ exposure to TCDD. This is consistent with the view that TIPARP overexpression is linked to the AhR repression pathway.

Cytochrome P4501B1 (CYP1B1) was among the genes that were differentially expressed. In most studies the action of TCDD in human cells or in animal models show that both CYP1A1 as CYP1B1 are overexpressed when exposed to this toxic agent (Mimura and FujiiKuriyama, 2003; Puebla-Osorio et al., 2004; Wu et al., 2004). Interestingly, as presented above, only CYP1B1 and not CYP1A1 was overexpressed as a result of the AhR activation by TCDD. These differences are intriguing considering that previous studies have focused on shortterm (acute) exposure while our study was the first to analyze the effect of TCDD in human Sertoli cells using a long (72 h) exposure, modelling chronic exposure. Computational analysis by miRWalk, predicted miR3613-3p as a modulator of CYP1B1 gene expression. As expected, miR3613-3p was down regulated while the target gene was up regulated and overexpressed. Importantly, CYP1B1 has been linked to the conversion of 17B-estradiol to 4-hydroxyestradiol, in addition to the bioactivation of many polycyclic aromatic hydrocarbons (PAHs) (Hayes et al., 1996). Estradiol 4-hydroxylation activity is elevated in breast and uterine tumors, relative to surrounding tissues. In addition to mutagen activation (Liehr et al., 1995) this suggests that CYP1B1 may play a more active role in tumorigenesis. Although one study reported the involvement of this gene in germ cell cancer (Starr et al., 2005), researches still need to be conducted to evaluate the relationship between CYP1B1 and testicular Sertoli cell tumor. On one hand, Mandal et al indicated that CYP1B1 did not contribute to the development of Leydig cells tumor (Mandal et al., 2001). On the other hand, O'Neill et al. (O'Neill et al., 2015) showed up-regulation of TIPARP in LNCap cells (human prostate adenocarcinoma cells) compared to control cells. Perhaps, the up regulation of TIPARP and CYP1B1 reflects TCDD's role in Sertoli cells tumorigenesis.

Sertoli cells play a pivotal role in creating microenvironments essential for spermatogonial stem cells (SSCs) self-renewal and commitment to differentiation (Rastegar et al., 2015). Leukaemia inhibitory factor (LIF) is reported to be essential component for long-term culture of primordial germ cell and embryonic germ cell as well as their survival by preventing them from apoptosis. Its combination with bFGF (basic fibroblast growth factor) has been expected to elicit much higher effect (Mirzapour et al., 2012). LIF acts through STAT3, which dimers are translocated to the nucleus where they bind to sites on the DNA controlling the transcription of genes important in stem cells self-renewal in the presence of serum (Davey et al., 2007). Fibroblast growth factor 2, FGF2/bFGF, is expressed and secreted by mammalian Sertoli cells and stimulates SSC self-renewal (Chen and Liu, 2015). Similary, after a $72 \mathrm{~h}$ TCDD exposure, human Sertoli cells FGF2 was up regulated and miR-3613-3p down regulated. Zhang et al. (2012) indicated that FGF2 might regulate mouse SSC proliferation and stem cell activity in vitro via autocrine phosphorylation of the AKT and ERK1/2 pathways. A conditional FGF2 Sertoli cell postnatal knockout could help to elucidate the role of FGF2 in SSC self-renewal in vivo. Therefore, the overexpression of these two crucial genes for SSC proliferation could disrupt the spermatogenesis process and may ultimately lead to infertility.

GPR68 is also dysregulated in response to TCDD exposure. G protein-coupled receptor 68/ ORC1 (Ovarian Cancer-Related Protein 1) is a proton-sensing receptor involved in $\mathrm{pH}$ homeostasis (Parry et al., 2016). It also functions as a prostate cancer metastasis suppressor gene, involved in the inflammatory response (Parry et al., 2016). Its action is mediated by association with $\mathrm{G}$ proteins that stimulate inositol phosphate (IP) production and release calcium from intracellular stores (Ludwig et al., 2003) upon acidification. A recent study in Caco-2 cells, an intestinal barrier model, showed that overexpression of GPR68, increased barrier formation upon acidification of the environment (de Vallière et al., 2015). Similarly, the Sertoli BTB requires pH stability. Interestingly, GPR68 is upregulated in human Sertoli cells after a $72 \mathrm{~h}$ TCDD exposure and like the other transcripts its corresponding miR$18 \mathrm{a}-3 \mathrm{p}$ is down regulated, again suggesting a regulatory pathway. This likely defines GPR68's role in maintaining the BTB.

Our data showed that there are important key proteins altered in human Sertoli cells after chronic exposure to TCDD: GPR68, FGF2 and LIF are upregulated, and therefore BTB maintenance and SSC proliferation could be compromised. Several stress pathway responsive genes are up regulated triggering genes as IL1A, IL1B that are also involved in inflammatory response as well as part of cancer related pathways (Chen et al., 2015; Pio, 2015). Other pathways, such as proliferation, signaling, cell growth and development, are affected and directly related to specific functions of AhR (Tian et al., 2015). As we have shown TCDD represses the TIPARP pathway and not the AHRR 
canonical pathway where mir-106b-5p effectively blocks AHRR. This has opened the door to new perspectives on the TCDD toxicity pathway as it affects Sertoli cells physiology that can ultimately lead to male infertility.

\section{Funding}

This work was supported by São Paulo State Research Foundation (FAPESP) [grant number 2013/12154-2].

\section{Appendix A. Supplementary data}

Supplementary material related to this article can be found, in the online version, at doi:https://doi.org/10.1016/j.tox.2018.08.001.

\section{References}

Abu-Halima, M., Hammadeh, M., Schmitt, J., Leidinger, P., Keller, A., Meese, E., Backes, C., 2013. Altered microRNA expression profiles of human spermatozoa in patients with different spermatogenic impairments. Fertil. Steril. 99, 1249-1255. https://doi. org/10.1016/j.fertnstert.2012.11.054. e16.

Aly, H.A.A., Khafagy, R.M., 2011. 2,3,7,8-tetrachlorodibenzo-p-dioxin (TCDD)-induced cytotoxicity accompanied by oxidative stress in rat Sertoli cells: Possible role of mitochondrial fractions of Sertoli cells. Toxicol. Appl. Pharmacol. 252, 273-280. https://doi.org/10.1016/j.taap.2011.02.019.

Anders, S., Huber, W., 2010. Differential expression analysis for sequence count data. Genome Biol. 11, R106. https://doi.org/10.1186/gb-2010-11-10-r106.

Anders, G., Mackowiak, S.D., Jens, M., Maaskola, J., Kuntzagk, A., Rajewsky, N., Landthaler, M., Dieterich, C., 2012. doRiNA: a database of RNA interactions in posttranscriptional regulation. Nucleic Acids Res. 40, D180-6. https://doi.org/10.1093/ nar/gkr1007.

Anders, S., Pyl, P.T., Huber, W., 2014. HTSeq A Python framework to work with highthroughput sequencing data. bioRxiv 31, 2824. https://doi.org/10.1101/002824.

Andrews, S., 2010. FastQC A Quality Control Tool for High Throughput Sequence Data. [WWW Document]. URL. http://www.bioinformatics.babraham.ac.uk/projects/ fastqc/.

Bartel, D.P., Lee, R., Feinbaum, R., 2004. MicroRNAs : Genomics, Biogenesis, Mechanism, and Function. Cell 116, 281-297.

Benjamini, Y., Hochberg, Y., 1995. Controlling the false discovery rate: a practical and powerful approach to multiple testing. J. R. Stat. Soc. https://doi.org/10.2307/ 2346101.

Bertazzi, P.A., Consonni, D., Bachetti, S., Rubagotti, M., Baccarelli, A., Zocchetti, C., Pesatori, A.C., 2001. Health effects of dioxin exposure: a 20 -year mortality study. Am. J. Epidemiol. 153, 1031-1044.

Betel, D., Wilson, M., Gabow, A., Marks, D.S., Sander, C., 2008. The microRNA.org resource: targets and expression. Nucleic Acids Res. 36, 149-153. https://doi.org/10. 1093/nar/gkm995.

Boekelheide, K., 2005. Mechanisms of toxic damage to spermatogenesis. J. Natl. Cancer Inst. Monogr. 6-8. https://doi.org/10.1093/jncimonographs/lgi006.

Chen, S.R., Liu, Y.X., 2015. Regulation of spermatogonial stem cell self-renewal and spermatocyte meiosis by Sertoli cell signaling. Reproduction 149, R159-R167. https://doi.org/10.1530/REP-14-0481.

Chen, C., Khaleel, S.S., Huang, H., Wu, C.H., 2014. Software for pre-processing Illumina next-generation sequencing short read sequences. Source Code Biol. Med. 9 (8). https://doi.org/10.1186/1751-0473-9-8.

Chen, S.-T., Chen, D.-R., Fang, J.-P., Lin, P.-H., 2015. 2,3,7,8-Tetrachlorodibenzo-p-dioxin modulates estradiol-induced aldehydic DNA lesions in human breast cancer cells through alteration of CYP1A1 and CYP1B1 expression. Breast Cancer 22, 269-279. https://doi.org/10.1007/s12282-013-0476-0.

Croxford, T.P., McCormick, N.H., Kelleher, S.L., 2011. Moderate zinc deficiency reduces testicular Zip6 and Zip10 abundance and impairs spermatogenesis in mice. J. Nutr 141, 359-365. https://doi.org/10.3945/jn.110.131318.

Davey, R.E., Onishi, K., Mahdavi, A., Zandstra, P.W., 2007. LIF-mediated control of embryonic stem cell self-renewal emerges due to an autoregulatory loop. FASEB J. 21, 2020-2032. https://doi.org/10.1096/fj.06-7852com.

de Freitas, A.T.A.G., Ribeiro, M.A., Pinho, C.F., Peixoto, A.R., Domeniconi, R.F., Scarano, W.R., 2016. Regulatory and junctional proteins of the blood-testis barrier in human sertoli cells are modified by monobutyl phthalate (MBP) and bisphenol A (BPA) exposure. Toxicol. In Vitro 34, 1-7. https://doi.org/10.1016/j.tiv.2016.02.017.

de Vallière, C., Vidal, S., Clay, I., Jurisic, G., Tcymbarevich, I., Lang, S., Ludwig, M.-G., Okoniewski, M., Eloranta, J.J., Kullak-Ublick, G.A., Wagner, C.A., Rogler, G., Seuwen, K., 2015. The pH-sensing receptor OGR1 improves barrier function of epithelial cells and inhibits migration in an acidic environment. Am. J. Physiol. Gastrointest. Liver Physiol. 309, G475-90. https://doi.org/10.1152/ajpgi.00408. 2014.

Denison, M.S., Nagy, S.R., 2003. Activation of the aryl hydrocarbon receptor by structurally diverse exogenous and endogenous chemicals. Annu. Rev. Pharmacol. Toxicol. 43, 309-334. https://doi.org/10.1146/annurev.pharmtox.43.100901. 135828.

Dweep, H., Sticht, C., Pandey, P., Gretz, N., 2011a. miRWalk-database: prediction of possible miRNA binding sites by \&quot;walking\&quot; the genes of three genomes. J. Biomed. Inform. 44, 839-847. https://doi.org/10.1016/j.jbi.2011.05.002.

Dweep, H., Sticht, C., Pandey, P., Gretz, N., 2011b. miRWalk-database: prediction of possible miRNA binding sites by "walking" the genes of three genomes. J. Biomed. Inform. 44, 839-847. https://doi.org/10.1016/j.jbi.2011.05.002.

Forgacs, A.L., Dere, E., Angrish, M.M., Zacharewski, T.R., 2013. Comparative analysis of temporal and dose-dependent TCDD-elicited gene expression in human, mouse, and rat primary hepatocytes. Toxicol. Sci. 133, 54-66. https://doi.org/10.1093/toxsci/ kft028.

Friedman, R.C., Farh, K.K.-H., Burge, C.B., Bartel, D.P., 2009. Most mammalian mRNAs are conserved targets of microRNAs. Genome Res. 19, 92-105. https://doi.org/10. 1101/gr.082701.108.

Gao, Y., Mruk, D.D., Cheng, C.Y., 2015. Sertoli cells are the target of environmental toxicants in the testis - a mechanistic and therapeutic insight. Expert Opin. Ther. Targets 19, 1073-1090. https://doi.org/10.1517/14728222.2015.1039513.

Gentleman, R.C., Gentleman, R.C., Carey, V.J., Carey, V.J., Bates, D.M., Bates, D.M., Bolstad, B., Bolstad, B., Dettling, M., Dettling, M., Dudoit, S., Dudoit, S., Ellis, B., Ellis, B., Gautier, L., Gautier, L., Ge, Y., Ge, Y., Gentry, J., Gentry, J., Hornik, K., Hornik, K., Hothorn, T., Hothorn, T., Huber, W., Huber, W., Iacus, S., Iacus, S., Irizarry, R. Irizarry, R., Leisch, F., Leisch, F., Li, C., Li, C., Maechler, M., Maechler, M., Rossini, A.J., Rossini, A.J., Sawitzki, G., Sawitzki, G., Smith, C., Smith, C., Smyth, G., Smyth, G., Tierney, L., Tierney, L., Yang, J.Y.H., Yang, J.Y.H., Zhang, J., Zhang, J., 2004. Bioconductor: open software development for computational biology and bioinformatics. Genome Biol. 5, R80. https://doi.org/10.1186/gb-2004-5-10-r80.

Hansen, D.A., Esakky, P., Drury, A., Lamb, L., Moley, K.H., 2014. The aryl hydrocarbon receptor is important for proper seminiferous tubule architecture and sperm development in mice. Biol. Reprod. 90 (1), 8. https://doi.org/10.1095/biolreprod.113. 108845. (online 2013).

Harrad, S., Wang, Y., Sandaradura, S., Leeds, A., 2003. Human dietary intake and excretion of dioxin-like compounds. J. Environ. Monit. 5, 224-228.

Hayes, C.L., Spink, D.C., Spink, B.C., Cao, J.Q., Walker, N.J., Sutter, T.R., 1996. 17 betaestradiol hydroxylation catalyzed by human cytochrome P450 1B1. Proc. Natl. Acad. Sci. U. S. A. 93, 9776-9781.

Houlahan, K.E., Prokopec, S.D., Moffat, I.D., Lindén, J., Lensu, S., Okey, A.B., Pohjanvirta, R., Boutros, P.C., 2015. Transcriptional profiling of rat hypothalamus response to 2,3,7,8-tetrachlorodibenzo- $\rho$-dioxin. Toxicology 328, 93-101. https://doi.org/10. 1016/j.tox.2014.12.016.

Hsu, S.-D., Chu, C.-H., Tsou, A.-P., Chen, S.-J., Chen, H.-C., Hsu, P.W.-C., Wong, Y.-H., Chen, Y.-H., Chen, G.-H., Huang, H.-D., 2008. miRNAMap 2.0: genomic maps of microRNAs in metazoan genomes. Nucleic Acids Res. 36, D165-D169. https://doi. org $/ 10.1093 / \mathrm{nar} / \mathrm{gkm} 1012$.

Jackson, D.P., Mitchell, K.A., 2011. Ah Receptor - Mediated Suppression of Liver Regeneration Through NC- XRE - Driven p21 Cip1 Expression.

Kent, W.J., Sugnet, C.W., Furey, T.S., Roskin, K.M., Pringle, T.H., Zahler, A.M., Haussler, D., 2002. The human genome browser at UCSC. Genome Res. 12, 996-1006. https:// doi.org/10.1101/gr.229102. Article published online before print in May 2002.

Kertesz, M., Iovino, N., Unnerstall, U., Gaul, U., Segal, E., 2007. The role of site accessibility in microRNA target recognition. Nat. Genet. 39, 1278-1284. https://doi.org/ 10.1038/ng2135.

Kim, D., Langmead, B., Salzberg, S.L., 2015. HISAT: a fast spliced aligner with low memory requirements. Nat. Methods 12, 357-360. https://doi.org/10.1038/nmeth. 3317.

Lai, K.P., Wong, M.H., Wong, C.K.C., 2005. Effects of TCDD in modulating the expression of Sertoli cell secretory products and markers for cell-cell interaction. Toxicology 206, 111-123. https://doi.org/10.1016/j.tox.2004.07.002.

Langmead, B., Trapnell, C., Pop, M., Salzberg, S.L., 2009. Ultrafast and memory-efficient alignment of short DNA sequences to the human genome. Genome Biol. 10, R25. https://doi.org/10.1186/gb-2009-10-3-r25.

Leng, N., Li, Y., McIntosh, B.E., Nguyen, B.K., Duffin, B., Tian, S., Thomson, J.A., Dewey, C.N., Stewart, R., Kendziorski, C., 2015. EBSeq-HMM: a Bayesian approach for identifying gene-expression changes in ordered RNA-seq experiments. Bioinformatics 31, 2614-2622. https://doi.org/10.1093/bioinformatics/btv193.

Li, B., Dewey, C.N., 2011. RSEM: accurate transcript quantification from RNA-Seq data with or without a reference genome. BMC Bioinf. 12 (323). https://doi.org/10.1186/ 1471-2105-12-323.

Lian, J., Zhang, X., Tian, H., Liang, N., Wang, Y., Liang, C., Li, X., Sun, F., 2009. Altered microRNA expression in patients with non-obstructive azoospermia. Reprod. Biol. Endocrinol. 11, 7-13. https://doi.org/10.1186/1477-7827-7-13.

Liehr, J.G., Ricci, M.J., Jefcoate, C. R., Hannigan, E.V., Hokanson, J A., Zhu, B.T., 1995. 4. Hydroxylation of estradiol by human uterine myometrium and myoma microsomes: implications for the mechanism of uterine tumorigenesis. Proc. Natl. Acad. Sci. U. S. A. 92, 9220-9224.

Livak, K.J., Schmittgen, T.D., 2001. Analysis of relative gene expression data using realtime quantitative PCR and the 2(-Delta Delta C(T)) Method. Methods 25, 402-408. https://doi.org/10.1006/meth.2001.1262.

Loher, P., Rigoutsos, I., 2012. Interactive exploration of RNA22 microRNA target predictions. Bioinformatics 28, 3322-3323. https://doi.org/10.1093/bioinformatics/ bts615.

Ludwig, M.-G., Vanek, M., Guerini, D., Gasser, J.A., Jones, C.E., Junker, U., Hofstetter, H., Wolf, R.M., Seuwen, K., 2003. Proton-sensing G-protein-coupled receptors. Nature 425, 93-98. https://doi.org/10.1038/nature01905.

Lui, W.-Y., Wong, C.-H., Mruk, D.D., Cheng, C.Y., 2003. TGF- 33 regulates the blood-testis barrier dynamics via the p38 Mitogen Activated Protein (MAP) kinase pathway: an in Vivo study. Endocrinology 144, 1139-1142. https://doi.org/10.1210/en.2002-0211.

Luna, A., Sunshine, M.L., van Iersel, M.P., Aladjem, M.I., Kohn, K.W., 2011. PathVisioMIM: PathVisio plugin for creating and editing Molecular Interaction Maps (MIMs). 
Bioinformatics 27, 2165-2166. https://doi.org/10.1093/bioinformatics/btr336.

MacPherson, L., Tamblyn, L., Rajendra, S., Bralha, F., McPherson, J.P., Matthews, J., 2013a. 2,3,7,8-Tetrachlorodibenzo-p-dioxin poly(ADP-ribose) polymerase (TiPARP, ARTD14) is a mono-ADP-ribosyltransferase and repressor of aryl hydrocarbon receptor transactivation. Nucleic Acids Res. 41, 1604-1621. https://doi.org/10.1093/ nar/gks1337.

MacPherson, L., Tamblyn, L., Rajendra, S., Bralha, F., McPherson, J.P., Matthews, J., 2013b. 2,3,7,8-Tetrachlorodibenzo-p-dioxin poly(ADP-ribose) polymerase (TiPARP, ARTD14) is a mono-ADP-ribosyltransferase and repressor of aryl hydrocarbon receptor transactivation. Nucleic Acids Res. 41, 1604-1621. https://doi.org/10.1093/ nar/gks1337.

MacPherson, L., Ahmed, S., Tamblyn, L., Krutmann, J., Förster, I., Weighardt, H., Matthews, J., 2014. Aryl hydrocarbon receptor repressor and TiPARP (ARTD14) use similar, but also distinct mechanisms to repress aryl hydrocarbon receptor signaling. Int. J. Mol. Sci. 15, 7939-7957. https://doi.org/10.3390/ijms15057939.

Malisch, R., Kotz, A., 2014. Dioxins and PCBs in feed and food-review from European perspective. Sci. Total Environ. 491-492, 2-10. https://doi.org/10.1016/j.scitotenv. 2014.03.022.

Mandal, P.K., McDaniel, L.R., Prough, R.A., Clark, B.J., 2001. 7,12-Dimethylbenz[a]anthracene inhibition of steroid production in MA-10 mouse Leydig tumor cells is not directly linked to induction of CYP1B1. Toxicol. Appl. Pharmacol. (175), 200-208. https://doi.org/10.1006/taap.2001.9241.

Maragkakis, M., Reczko, M., Simossis, V.A., Alexiou, P., Papadopoulos, G.L., Dalamagas, T., Giannopoulos, G., Goumas, G., Koukis, E., Kourtis, K., Vergoulis, T., Koziris, N., Sellis, T., Tsanakas, P., Hatzigeorgiou, A.G., 2009. DIANA-microT web server: elucidating microRNA functions through target prediction. Nucleic Acids Res. 37 273-276. https://doi.org/10.1093/nar/gkp292.

Mimura, J., Fujii-Kuriyama, Y., 2003. Functional role of AhR in the expression of toxic effects by TCDD. Biochim. Biophys. Acta 1619, 263-268.

Mirzapour, T., Movahedin, M., Tengku Ibrahim, T.A., Koruji, M., Haron, A.W., Nowroozi, M.R., Rafieian, S.H., 2012. Effects of basic fibroblast growth factor and leukaemia inhibitory factor on proliferation and short-term culture of human spermatogonial stem cells. Andrologia 44, 41-55. https://doi.org/10.1111/j.1439-0272.2010. 01135.x.

Mosmann, T., 1983. Rapid colorimetric assay for cellular growth and survival: application to proliferation and cytotoxicity assays. J. Immunol. Methods 65, 55-63.

Mruk, D.D., Cheng, C.Y., 2004. Sertoli-Sertoli and Sertoli-germ cell interactions and their significance in germ cell movement in the seminiferous epithelium during spermatogenesis. Endocr. Rev. 25, 747-806. https://doi.org/10.1210/er.2003-0022.

O'Neill, D., Jones, D., Wade, M., Grey, J., Nakjang, S., Guo, W., Cork, D., Davies, B.R., Wedge, S.R., Robson, C.N., Gaughan, L., 2015. Development and exploitation of a novel mutant androgen receptor modelling strategy to identify new targets for advanced prostate cancer therapy. Oncotarget 6, 26029-26040. https://doi.org/10. 18632 /oncotarget 4347.

Parry, D.A., Smith, C.E.L., El-Sayed, W., Poulter, J.A., Shore, R.C., Logan, C.V., Mogi, C., Sato, K., Okajima, F., Harada, A., Zhang, H., Koruyucu, M., Seymen, F., Hu, J.C.-C., Simmer, J.P., Ahmed, M., Jafri, H., Johnson, C.A., Inglehearn, C.F., Mighell, A.J., 2016. Mutations in the pH-sensing G-protein-coupled receptor GPR68 cause amelogenesis imperfecta. Am. J. Hum. Genet. https://doi.org/10.1016/j.ajhg.2016.08.020.

Pio, R., 2015. HHS Public Access. pp. 229-262. https://doi.org/10.1007/978-1-4614 5915-6.

Pompa, G., Caloni, F., Fracchiolla, M.L., 2003. Dioxin and PCB contamination of fish and shellfish: assessment of human exposure. Review of the international situation. Vet. Res. Commun. 27 (Suppl. 1), 159-167.

Puebla-Osorio, N., Ramos, K.S., Falahatpisheh, M.H., Smith, R., Berghman, L.R., 2004 2,3,7,8-Tetrachlorodibenzo-p-dioxin elicits aryl hydrocarbon receptor-mediated apoptosis in the avian DT40 pre-B-cell line through activation of caspases 9 and 3 . Comp. Biochem. Physiol. C Toxicol. Pharmacol. 138, 461-468. https://doi.org/10. 1016/j.cca.2004.08.002

Qiu, L., Zhang, X., Zhang, X., Zhang, Y., Gu, J., Chen, M., Zhang, Z., Wang, X., Wang, S.-L., 2013. Sertoli cell is a potential target for perfluorooctane sulfonate-induced reproductive dysfunction in male mice. Toxicol. Sci. 135, 229-240. https://doi.org/10. 1093/toxsci/kft129.

Rastegar, T., Roudkenar, H., Parvari, S., Baazm, M., 2015. The interaction between sertoli cells and luekemia inhibitory factor on the propagation and differentiation of spermatogonial stem cells in vitro. Iran. J. Reprod. Med. 13, 679-686.

Rehmsmeier, M., Steffen, P., Hochsmann, M., Giegerich, R., 2004. Fast and effective prediction of microRNA/target duplexes. RNA 10, 1507-1517. https://doi.org/10. 1261/rna.5248604.

Robinson, M.D., Oshlack, A., 2010. A scaling normalization method for differential expression analysis of RNA-seq data. Genome Biol. 11, R25. https://doi.org/10.1186/ gb-2010-11-3-r25.

Robinson, M.D., McCarthy, D.J., Smyth, G.K., 2010. edgeR: a Bioconductor package for differential expression analysis of digital gene expression data. Bioinformatics 26 , 139-140. https://doi.org/10.1093/bioinformatics/btp616.

Rueda, A., Barturen, G., Lebrón, R., Gómez-Martín, C., Alganza, Á, Oliver, J.L., Hackenberg, M., 2015. sRNAtoolbox: an integrated collection of small RNA research tools. Nucleic Acids Res. 43, W467-73. https://doi.org/10.1093/nar/gkv555.

Schecter, A., Pavuk, M., Amirova, D.A., Grosheva, E.I., Päpke Ryan, J.J., Adibi, J., Piskac, A.L., 2002. Characterization of dioxin exposure in firefighters, residents, and chemical workers in the Irkutsk Region of Russian Siberia. Chemosphere 47, 147-156.

Sharpe, R.M., McKinnell, C., Kivlin, C., Fisher, J.S., 2003. Proliferation and functional maturation of Sertoli cells, and their relevance to disorders of testis function in adulthood. Reproduction 125, 769-784. https://doi.org/10.1530/reprod/125.6.769.

Sikka, S.C., Wang, R., 2008. Endocrine disruptors and estrogenic effects on male reproductive axis. Asian J. Androl. 10, 134-145. https://doi.org/10.1111/j.1745-7262. 2008.00370.x

Starr, J.R., Chen, C., Doody, D.R., Hsu, L., Ricks, S., Weiss, N.S., Schwartz, S.M., 2005 Risk of testicular germ cell cancer in relation to variation in maternal and offspring cytochrome p450 genes involved in catechol estrogen metabolism. Cancer Epidemiol. Biomarkers Prev. 14, 2183-2190. https://doi.org/10.1158/1055-9965.EPI-04-0749.

Tian, J., Feng, Y., Fu, H., Xie, H.Q., Jiang, J.X., Zhao, B., 2015. The aryl hydrocarbon receptor: a key bridging molecule of external and internal chemical signals. Environ. Sci. Technol. 49, 9518-9531. https://doi.org/10.1021/acs.est.5b00385.

Tsang, J., Ebert, M.A., van, O., 2010. Targeting networks using gene-set signatures. Mol. Cell 38, 140-153. https://doi.org/10.1016/j.molcel.2010.03.007.Genome-wide.

Vejnar, C.E., Blum, M., Zdobnov, E.M., 2013. miRmap web: Comprehensive microRNA target prediction online. Nucleic Acids Res. 41, W165-8. https://doi.org/10.1093/ nar/gkt430.

Warner, M., Mocarelli, P., Brambilla, P., Wesselink, A., Samuels, S., Signorini, S., Eskenazi, B., 2013. Diabetes, metabolic syndrome, and obesity in relation to serum dioxin concentrations: the Seveso women's health study. Environ. Health Perspect. 121, 906-911. https://doi.org/10.1289/ehp.1206113.

Weber, J.E., Russell, L.D., Wong, V., Peterson, R.N., 1983. Three-dimensional reconstruction of a rat stage V Sertoli cell: II. Morphometry of Sertoli-Sertoli and Sertoli-germ-cell relationships. Am. J. Anat. 167, 163-179. https://doi.org/10.1002/ aja.1001670203.

Wolf, C.J., Ostby, J.S., Gray, L.E., 1999. Gestational exposure to 2,3,7,8-tetrachlorodibenzo-p-dioxin (TCDD) severely alters reproductive function of female hamster offspring. Toxicol. Sci. 51, 259-264.

Wong, N., Wang, X., 2015. miRDB: an online resource for microRNA target prediction and functional annotations. Nucleic Acids Res. 43, D146-52. https://doi.org/10.1093/ nar/gku1104.

Wu, Q., Ohsako, S., Ishimura, R., Suzuki, J.S., Tohyama, C., 2004. Exposure of mouse preimplantation embryos to 2,3,7,8-tetrachlorodibenzo-p-dioxin (TCDD) alters the methylation status of imprinted genes H19 and Igf2. Biol. Reprod. 70, 1790-1797. https://doi.org/10.1095/biolreprod.103.025387.

Xiao, X., Mruk, D.D., Tang, E.I., Wong, C.K.C., Lee, W.M., John, C.M., Turek, P.J., Silvestrini, B., Cheng, C.Y., 2014. Environmental toxicants perturb human Sertoli cell adhesive function via changes in F-actin organization mediated by actin regulatory proteins. Hum. Reprod. 29, 1279-1291. https://doi.org/10.1093/humrep/deu011.

Zhang, Y., Wang, S., Wang, X., Liao, S., Wu, Y., Han, C., 2012. Endogenously produced FGF2 is essential for the survival and proliferation of cultured mouse spermatogonial stem cells. Cell Res. 22, 773-776. https://doi.org/10.1038/cr.2012.17. 